\title{
Infection dynamics of Lernaeocera lusci on sand goby Pomatoschistus minutus in the Oosterschelde (The Netherlands)
}

\author{
P. A. Van Damme, F. Ollevier
}

Laboratory for Ecology and Aquaculture, Zoological Institute, Naamsestraat 59, B-3000 Leuven, Belgium

\begin{abstract}
Male and female sand gobies Pomatoschistus minutus (Pallas) from the Oosterschelde (The Netherlands) were examined for the crustacean mesoparasite Lernaeocera lusci (Bassett-Smith) from April to July 1992. Prevalence increased steeply from $4 \%$ in April to $80 \%$ (females) and $57 \%$ (males) in June. The peak abundance of recently attached infective stages (pennella larvae) on sand gobies was found in May. By June, about $70 \%$ of parasites were in the post-metamorphosis stage and possessed egg strings. Significant differences in abundance between males and females were found in June but not in May. This may be due to sex-specific differences in behaviour during spawning time. The majority of post-spawning fish probably died in July. Fish of the new year class which were captured in July harboured no parasites.
\end{abstract}

KEY WORDS: Pomatoschistus minutus Lernaeocera lusci Parasitism Oosterschelde

\section{INTRODUCTION}

Lernaeocera lusci (Bassett-Smith) is a crustacean parasite which uses sole Solea solea as intermediate host. Though bib Trisopterus luscus is the typical definitive host, adult females can also be found attached to many other demersal fish species (Boxshall 1974, Kabata 1979, Tirard 1991). L. minuta, which was previously distinguished from $L$. lusci on grounds of its small size (Kabata 1979), can be equalled to L. lusci because of the host-dependency of parasite size (Van Damme et al. 1993). Sand goby Pomatoschistus minutus (Pallas), which was previously considered to be the typical host species of $L$. minuta, thus appears on the host list of L. Iusci.

High prevalences of Lernaeocera minuta (henceforth L. lusci) have been recorded on sand gobies along the German coast ( $86 \%$ by Mann 1964, $22 \%$ by Petersen $1992)$ and along the Belgian coast $(39 \%$ by Hamerlynck et al. 1989). In the Belgian as well as in the southwestern Dutch coastal area, 2 transmission waves could be distinguished (Hamerlynck et al. 1989): a first wave occurred in late autumn when juvenile sand gobies were infected, and a second transmission wave occurred in the following spring when mature, spawning sand gobies were infected.
Mann (1964) and Petersen (1992) found that Lernaeocera lusci was responsible for a significant decrease in the condition factor of sand gobies. Moreover, both fat content of the liver and hemoglobin content were lower in infected gobies as compared to non-infected individuals (Mann 1964). However, neither study provided a detailed account of the dynamics of the host and parasite populations, though this may be essential for a better understanding of the interaction between host and parasite individuals. For example, fish size and fish sex were not considered, both of which may have acted as confounding variables in the investigàtions.

In this study, we provide further details on the infection dynamics of Lernaeocera lusci during the spring transmission wave in a tidal bay in the southern North Sea in 1992. In a future paper the effect of $L$. lusci on hematological parameters will be presented.

\section{MATERIAL AND METHODS}

Sand goby samples were collected in the western part of the Oosterschelde, a tidal bay in the southwest Netherlands. Surface water temperatures measured at 
Table 1. Pomatoschistus minutus. Sampling dates, water temperature, number of male, female and juvenile sand gobies caught, sex ratios (male:female) and mean total lengths ( $\mathrm{TL} \pm \mathrm{SD}$ ) in the Oosterschelde in 1992. The year class to which the fish belonged is indicated in parentheses. $F$ : ANOVA to test for differences in mean length between males and females (ns = not significant)

\begin{tabular}{|c|c|c|c|c|c|c|c|c|c|}
\hline \multirow{2}{*}{$\begin{array}{l}\text { Sampling } \\
\text { date }\end{array}$} & \multirow{2}{*}{$\begin{array}{l}\text { Water temp. } \\
\qquad\left({ }^{\circ} \mathrm{C}\right)\end{array}$} & \multicolumn{2}{|c|}{ Males (1991) } & \multicolumn{2}{|c|}{ Females (1991) } & \multicolumn{2}{|c|}{ Juveniles (1992) } & \multirow[t]{2}{*}{$F$} & \multirow{2}{*}{$\begin{array}{c}\text { Sex ratic } \\
M: F\end{array}$} \\
\hline & & $\mathrm{n}$ & $T L$ & $\mathrm{n}$ & $\mathrm{TL}$ & $\mathrm{n}$ & TL & & \\
\hline $6 \mathrm{Apr}$ & 9 & 17 & $65.4 \pm 6.4$ & 16 & $63.2 \pm 5.5$ & 0 & - & $1.14 \mathrm{~ns}$ & $52: 48$ \\
\hline $28 \mathrm{Apr}$ & 11 & 8 & $65.5 \pm 14.8$ & 10 & $62.7 \pm 2.2$ & 0 & - & - & $44: 56$ \\
\hline $15 \mathrm{May}$ & 12 & 38 & $66.3 \pm 8.0$ & 81 & $63.7 \pm 6.1$ & 0 & - & $3.33 \mathrm{~ns}$ & $32: 68$ \\
\hline $26 \mathrm{May}$ & 15 & 1 & 64.0 & 61 & $60.4 \pm 7.0$ & 0 & - & - & $2: 98$ \\
\hline $11 \mathrm{Jun}$ & 16 & 32 & $65.8 \pm 7.4$ & 46 & $63.6 \pm 5.3$ & 0 & - & $2.41 \mathrm{~ns}$ & $41: 59$ \\
\hline $4 \mathrm{Jul}$ & 18 & 3 & 62.2 & 1 & 64.1 & 31 & $41.2 \pm 2.2$ & - & $75: 25$ \\
\hline
\end{tabular}

the sampling sites increased from 9 to $18^{\circ} \mathrm{C}$ during the sampling period (Table 1).

On 6 April, 28 April, 26 May and 4 July the samples were taken with a commercial shrimp trawler using a $5 \mathrm{~m}$ beam trawl. The samples of 15 May and 11 June were taken with a research vessel using a $3 \mathrm{~m}$ beam trawl. All fish collected (except for some juvenile fish of the 1992 year class caught on 4 July) belonged to the 1991 year class. Due to the use of different sampling methods (e.g. differences in mesh size) the fish numbers do not reflect true densities.

On board, fish were anaesthesized in a benzocain solution and preserved in formalin $8 \%$. After about 5 mo the total length (to the nearest $\mathrm{mm}$ ) and total weight (to the nearest $\mathrm{mg}$ ) were determined. The GSI (gonadosomatic index) of the female fish collected on 6 April, 15 May and 11 June was calculated as follows:

$$
\text { GSI }=\frac{\text { Gonad weight }}{\text { Total body weight }- \text { Weight stomach content }}
$$

Prior to statistical analysis GSI was arcsine transformed.

The female parasites which were attached to the gill arches or in the gill cavity were counted and removed from the host. They were assigned to one of 8 developmental stages, based on the staging system of Van Damme \& Hamerlynck (1992) (Table 2). Prevalence (percentage of fish infected), abundance (mean number of parasites per fish), intensity (number of parasites on 1 host individual) and mean intensity (mean number of parasites per infected fish) were used according to the recommendations of Margolis et al. (1982). The relationship between the dependent variable parasite intensity $(y)$ and independent variables fish length $\left(x_{1}\right)$ and GSI $\left(x_{2}\right)$ of females on 13 May and 11 June was analysed by a multiple regression analysis:

$$
y=a+b_{1} x_{1}+b_{2} x_{2}
$$

where $a$ is the intercept, and $b_{1}$ and $b_{2}$ are regression coefficients.
Table 2. Classification of adult female Lemaeocera lusci on Pomatoschistus minutus (after Van Damme \& Hamerlynck 1992)

\begin{tabular}{|ll|}
\hline Substage & Definition \\
\hline Pennella (P1) & $\begin{array}{l}\text { Straight body, no flexure } \\
\text { Pennella (P2) }\end{array}$ \\
Immature (U) & $\begin{array}{l}\text { Two or three points of flexure } \\
\text { Genital region not swollen }\end{array}$ \\
Mature pregravid (W) & $\begin{array}{l}\text { Genital region fully swollen } \\
\text { No external egg strings }\end{array}$ \\
Mature gravid $(\mathrm{X})$ & External egg strings present \\
$\mathrm{X} 1$ & Immature eggs \\
$\mathrm{X} 2$ & Mature pigmented eggs \\
$\mathrm{Y}$ & External egg strings partly or \\
Dead parasite (Z) & completely spent \\
& Remains of holdfast embedded in \\
& host tissue \\
\hline
\end{tabular}

\section{RESULTS}

All fish collected before July belonged to the 1991 year class $(1+)$. In July this year class had all but disappeared and was replaced by fish belonging to the 1992 $(0+)$ year class. The numbers of female and male fish caught and sex ratios are given in Table 1. Between 4 April and 26 May the proportion of females in the catches increased progressively.

In all months, females were smaller than males, but these differences were not significant (ANOVA, $p>$ 0.05) (Table 1). Juveniles of year class 1992 which were collected on 4 July were significantly smaller than the $1+$ females (ANOVA; $F=166, p<0.001$ ) and the $1+$ males (ANOVA; $F=229, p<0.001$ ) of June 1992 (Table 1)

Prevalence and abundance of Lemaeocera lusci on female and male sand gobies are shown in Fig. 1. Prevalence steeply increased between 28 April and 15 May and then gradually increased to maximal levels of $77 \%$ (females) and $53 \%$ (males) in June. For both 

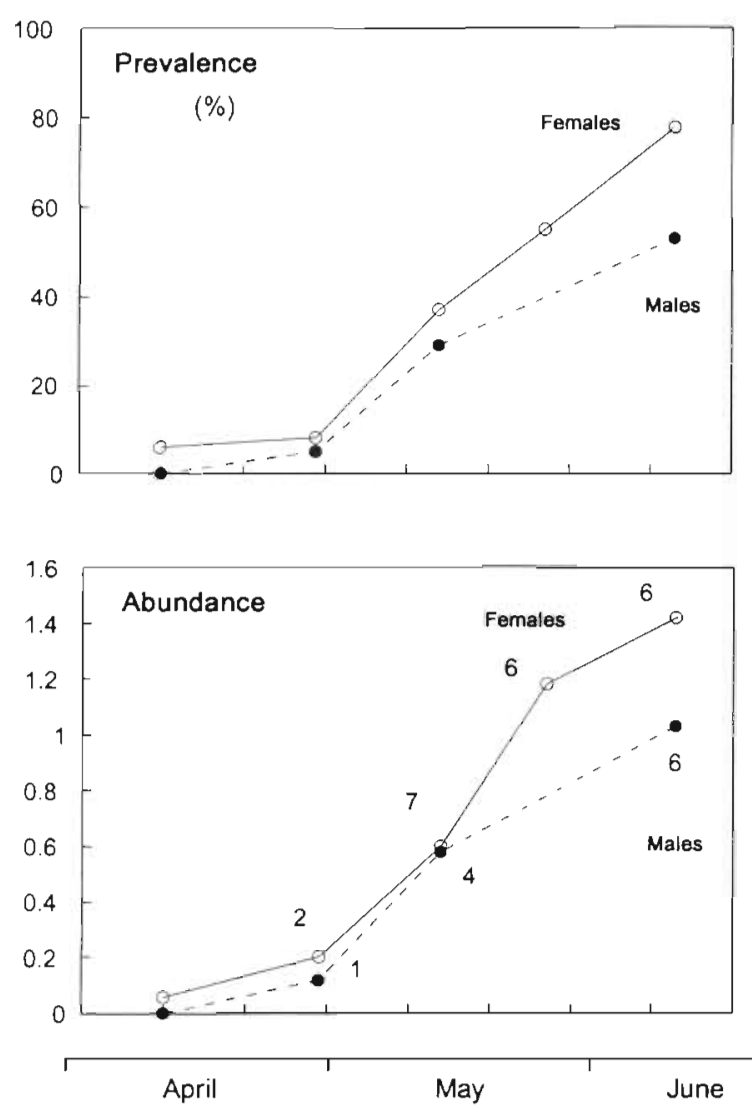

Fig. 1 Lernaeocera lusci infecting Pomatoschistus minutus Prevalence and abundance of parasites on female $(O)$ and male $(\bullet)$ sand gobies $P$. minutus in the Oosterschelde (The Netherlands) in 1992. The maximum number of parasites on individual males and females, respectively, is indicated for each sample

sexes there was a similar pattern for abundance: between the beginning of April and the end of June abundance increased from 0.06 to 1.77 (females) and from 0 to 1.42 (males). There were no significant differences in abundance between males and females on 28 April (Kruskal-Wallis; $H=0.23 ; \mathrm{p}>0.05$ ) and on 15 May $(H=0.27 ; \mathrm{p}>0.05)$. However, female sand gobies harboured significantly more parasites than males on 11 June $(H=4.03 ; \mathrm{p}<0.05)$. Fish with more than 4 parasites were found in May and June (Fig. 1).

Fish length and parasite intensity were positively correlated on 15 May and on 26 May for both males and females. On 28 April and 11 June the correlations between these 2 variables were not significant $(\mathrm{p}>$ 0.05) (Table 3).

The mean GSI for female gobies was significantly lower on 11 June $(0.05 \pm 0.05)$ than on 9 April $(0.08 \pm$ $0.03)$ and 15 May $(0.09 \pm 0.05)$ (Tukey test, $p<0.05$ ) (Fig. 2). The correlations between fish length and GSI were not significant on 15 May $(n=44, R=-0.24, p>$ $0.05)$ and on 11 June $(n=37, R=0.03, p>0.05)$.
Table 3. Lernaeocera lusci infecting Pomatoschistus minutus. Spearman Rank Correlations $(R)$ between fish length and parasite intensity for males and females in the Oosterschelde in spring 1992. ns: not significant; ${ }^{*} p<0.05 ;{ }^{*} p<0.01$

\begin{tabular}{|lcrc|}
\hline Date & Sex & $n$ & $R$ \\
\hline 28 Apr & F & 10 & $0.39 \mathrm{~ns}$ \\
& M & 8 & $-0.17 \mathrm{~ns}$ \\
15 May & F & 81 & $0.25^{\circ}$ \\
& M & 38 & $0.49^{\circ}$ \\
26 May & F & 61 & $0.41^{\cdots}$ \\
11 Jun & F & 45 & $0.19 \mathrm{~ns}$ \\
& M & 32 & $0.25 \mathrm{~ns}$ \\
\hline
\end{tabular}

Table 4. Lernaeocera lusci infecting Pomatoschistus minutus. Relationship between parasite intensity $(y)$, fish length $\left(x_{1}\right)$ and gonadosomatic index $\left\{x_{2}\right)$ according to the multiple regression equation $y=a+b_{1} x_{1}+b_{2} x_{2}$ on 15 May and on 11 June in the Oosterschelde in 1992. ns: not significant; $\cdots p<0.001$

\begin{tabular}{|crcc|}
\hline & $a$ & $b_{1}$ & $b_{2}$ \\
\hline 15 May & -5.55 & $0.11 \cdots$ & $-0.03 \mathrm{~ns}$ \\
11 Jun & 0.25 & $0.03 \mathrm{~ns}$ & $-0.05 \mathrm{~ns}$ \\
\hline
\end{tabular}

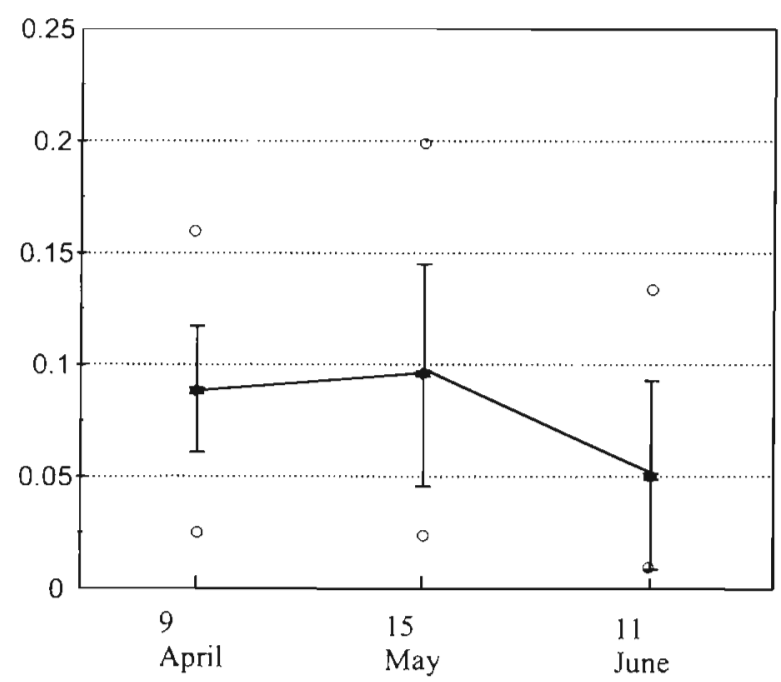

Fig. 2. Lernaeocera lusci infecting Pomatoschistus minutus Mean gonadosomatic index (GSI) of female sand goby between April and June 1992 in the Oosterschelde. SD, minima and maxima are indicated

Overall, the multiple regression equations between parasite intensity, GSI and fish length were significant on 15 May $(\mathrm{p}<0.01)$ but were not significant on 11 June $(p>0.05)$. Neither fish length nor GSI contributed significantly in the prediction of parasite intensity on 11 June (Table 4). 


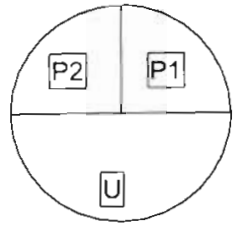

28 Aprii $(n=4)$

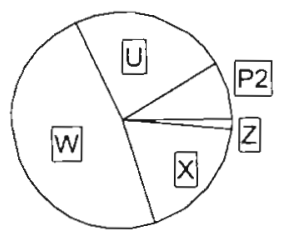

26 May $(n=46)$

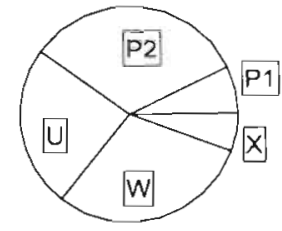

15 May $(n=12)$

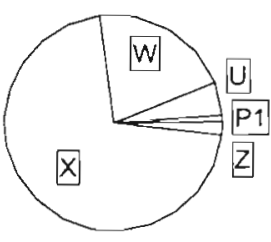

11 June $(n=42)$
Fig. 3. Lemaeocera lusci infecting Pomatoschistus minutus. Population structure of parasites on sand gobies on different sampling dates in the Oosterschelde in 1992. The number of parasites is indicated. For explanation of life cycle stages see Table 2

The population structure of Lernaeocera Iusci was characterised by a clear temporal pattern (Fig. 3). Juvenile stages (P1 and P2) were mainly found on 28 April and on 15 May, whereas adult female parasites with egg strings were found mainly after 28 May. This indicates that transmission occurred mainly prior to the latter dates. There was no clear temporal pattern in the occurrence of X1, X2 and Y substages. Overall, the majority ( $84 \%$ ) of adult female parasites belonged to the $\mathrm{X} 1$ substage.

\section{DISCUSSION}

After a short pelagic stage of approximately 1 mo, sand gobies start to live in close proximity to the bottom (Fonds 1973), and become increasingly susceptible to infection by Lemaeocera Iusci. In late autumn in the Belgian and Dutch coastal area, a small proportion $( \pm 10 \%)$ of this demersal sand goby population is infected with L. Iusci (Hamerlynck et al. 1989). These latter authors recorded no further infection in winter and a second, dramatic, rise in infection level during spawning time (May/June). The same seasonal pattern was apparently found in the present study: the few mature parasites which were found on gobies in the beginning of April had probably infected their hosts in the previous autumn. By June ca $80 \%$ of the females and $50 \%$ of the males were infected with $L$. lusci.

Sufficiently high temperatures and spatial overlap of intermediate and definitive hosts are 2 important prerequisites for succesful transmission of Lernaeocera lusci to definitive hosts. In both Hamerlynck et al. (1989) and the present study the maximum infection levels in late spring coincide with temperatures above $11^{\circ} \mathrm{C}$ (Table 1 ) and with the occurrence of intermediate hosts (soles) which harbour large numbers of adult pre-metamorphosis female $L$. Iusci (Van Damme \& Ollevier unpubl.). Because the majority of sand gobies die soon after spawning (Fonds 1973) there is a considerable reduction of parasite population size in July. However, in summer the role of definitive host is increasingly taken over by juvenile bib (Van Damme unpubl.). Along the German coast, highest infection levels were found in August/September (Mann 1964) or October (Petersen 1992). Because neither of these authors reported the size or possible age of the examined fish it is difficult to make a comparison. it appears that the spring transmission wave did not occur in the German coastal waters, perhaps due to differing transmission dynamics of infective pennella larvae within this area. Possibly, there is no spring overlap in the distribution of sand gobies and soles in the German Wadden Sea. More data on spatial distribution and temporal patterns in occurrence of sole in the area should be gathered before this hypothesis can be tested (Petersen 1992).

The significant difference in infection levels of males and females in late spring (11 June) may have resulted from sex-specific behavioural patterns during spawning time. The males of Pomatoschistus minutus build nests under bivalve shells which they cover completely with sand. They guard the eggs of 1 or more females until hatching (Fonds 1973, Hesthagen 1977). During egg guarding, male $P$. microps exhibit low feeding activities and hence reduced mobility (Magnhagen 1990). Fonds (1973), Magnhagen \& Kvarnemo (1989) and Hamerlynck \& Cattrijsse (in press) suggested this may also be the case in $P$. minutus. Furthermore, Hamerlynck \& Cattrijsse (in press) found that males consume predominantly Pomatoschistus eggs, polychaetes, bivalves and Gastrosaccus, which is a benthic mysid species. The hypothesis that males are often hiding in their nests (Hesthagen 1977, Magnhagen 1990) may also explain why sometimes small numbers of males are caught in early summer (Swedmark 1958). In the present study this was the case on 26 May when $98 \%(n=62)$ of the gobies were females (Table 1). On the other hand, females roam about during the spawning period (Hesthagen 1977. Hamerlynck \& Cattrijsse in press) with consequent higher probability of becoming infected by Lernaeocera lusci than the males. These sex-specific behavioural differences probably explain the different probabilities of males and females accumulating $L$. lusci.

Transmission of pennella larvae to sand gobies in spring is restricted to a very short period. Indeed, P1 
and P2 stages were predominantly found in 1 sample (May), whereas the June samples contained mainly mature parasites. The most plausible explanation for this apparently narrow transmission window was recently given: it was found that all infective stages of Lernaeocera lusci leave sole in a very short period, probably triggered by rising temperatures (Van Damme \& Ollevier unpubl.). Based on the present study we can provide some estimates for the duration of the life cycle stages of $L$. Iusci. The majority of the parasites which infected sand gobies after 28 April were mature by 11 June, suggesting a duration of 1 to 2 mo from initial infection to maturation.

In the present study no evidence for parasiteinduced host mortality nor for a relationship between parasite intensity and mating success of sand gobies was found. Hosts with more than 5 parasites were found at all sampling dates in May and June (Fig. 1), suggesting that heavily infected hosts suffer no high mortality during this sampling period. Hamerlynck et al. (1989) suggested that Lemaeocera lusci may further exacerbate the lowered condition of post-spawning sand gobies and hence induce post-spawning host mortality, but this could not be tested due to the small sample size in July. Furthermore, no significant correlation was found between the gonadosomatic index and the parasite intensity of females on 15 May and 11 June (Table 4). However, field sampling may be inadequate to find such a relationship. Probably, the female sand gobies are infected with $L$. Iusci at a time when they have already released 1 or more batches of eggs. The effect of these parasites on the reproductive success of the sand gobies, if present, may therefore be obscured by many confounding variables.

Acknowledgements. This research was supported by FKFOproject 20086.88 . P.A.V.D. received a grant from the National Science Foundation of Belgium (NFWO). N. Hoebeke is acknowledged for the use of the commercial vessel YE 75. C. Heip is acknowledged for the use of the RV 'Luctor' (NIOO).

Responsible Subject Editor: W. Körting, Hannover, Germany

\section{LITERATURE CITED}

Boxshall, G. A. (1974). Infections with parasitic copepods in North Sea marine fishes. J. mar. biol. Ass. U.K. 54: 355-372

Fonds, M. (1973). Sand gobies in the Dutch Wadden Sea (Pomatoschistus, Gobiidae, Pisces). Neth. J. Sea Res. 6: $417-478$

Hamerlynck, O., Cattrijsse, A. (in press). The food of Pomatoschistus minutus (Pisces, Gobiidae) in the Belgian coastal waters: a comparison with the food of its potential competitor P. lozanoi. J. Fish Biol

Hamerlynck, O., Geets, A., Van Damme, P. A. (1989). The parasites of two sympatric gobies Pomatoschistus minutus and $P$. lozanoi in the Belgian coastal waters. In: Wouters, K., Baert, K. (eds.) Comptes rendus du symposium 'Invertébrés de Belgique' KBIN, Brussels, p. 27-30

Hesthagen, I. H. (1977). Migrations, breeding and growth in Pomatoschistus minutus (Pallas) (Pisces, Gobiidae) in Oslofjorden, Norway. Sarsia 63: 17-26

Kabata, Z. (1979). Parasitic Copepoda of British fishes. The Ray Society, London

Magnhagen, C. (1990). Reproduction under predation risk in the sand goby, Pomatoschistus minutus, and the black goby, Gobius niger: the effect of age and longevity. Behav. Ecol. Sociobiol. 26: 331-335

Magnhagen, C., Kvarnemo, L. (1989). Big is better: the importance of size for reproductive success in male Pomatoschistus minutus (Pallas) (Pisces, Gobiidae). J. Fish Biol. 35: 755-763

Mann, H. (1964). Vorkommen, Verbreitung und Schadwirkung von Lernaeocera minuta T. Scott (Copepoda parasitica). Veröft. Inst. Meeresforsch. Bremershafen 9: 79-83

Margolis, L., Esch, G. W., Holmes, J. C., Kurie, A. M., Schad, G. A. (1982). The use of ecological terms in parasitology. J. Parasitol. 68: 131-133

Petersen, F. (1992). Nutritional condition and parasites of the sand goby Pomatoschistus minutus (Pallas) from the German Wadden Sea. Ophelia 35: 197-207

Swedmark, M. (1958). Sur la variation geographique de Gobius minutus Pallas. I. Biologie et croissance. Archs. Zool. exp. gén. 95, 32-51

Tirard, C. (1991). Biodiversité et biogéographie évolutive dans les systèmes hôtes-parasites: le modèle Gadiformes (Teleostéens) - Copépodes et Monogènes. Thèse de doctorat, Université de Montpellier

Van Damme, P. A., Hamerlynck, O. (1992). The infection dynamics and dispersion pattern of Lernaeocera branchialis on 0+ whiting (Merlangius merlangus L.) in the Oosterschelde (SW Netherlands). J. Fish Biol. 41: 265-275

Van Damme, P. A., Maertens, D., Arrumm, A., Hamerlynck, O., Ollevier, F. (1993). The role of Callionymus lyra and $C$. reticulatus in the life cycle of Lernaeocera lusci (BassettSmith). J. Fish Biol. 42: 395-401

Manuscript first received: October 29, 1993 Revised version accepted: April 20, 1994 